\title{
COVID-19 and its effects on neurological functions
}

\author{
Yew, M.M.T. ${ }^{1}$, Yip, J.Q. ${ }^{1}$, Ling, A.P.K. ${ }^{1 *}$ \\ ${ }^{1}$ Division of Applied Biomedical Sciences and Biotechnology, School of Health Sciences, International Medical University, Bukit Jalil, \\ 57000 Kuala Lumpur, Malaysia \\ *Corresponding author: anna_ling@imu.edu.my
}

\section{ARTICLE HISTORY}

Received: 19 June 2021

Revised: 11 August 2021

Accepted: 11 August 2021

Published: 30 September 2021

\begin{abstract}
Ever since the first reported case series on SARS-CoV-2-induced neurological manifestation in Wuhan, China in April 2020, various studies reporting similar as well as diverse symptoms of COVID-19 infection relating to the nervous system were published. Since then, scientists started to uncover the mechanism as well as pathophysiological impacts it has on the current understanding of the disease. SARS-CoV-2 binds to the ACE2 receptor which is present in certain parts of the body which are responsible for regulating blood pressure and inflammation in a healthy system. Presence of the receptor in the nasal and oral cavity, brain, and blood allows entry of the virus into the body and cause neurological complications. The peripheral and central nervous system could also be invaded directly in the neurogenic or hematogenous pathways, or indirectly through overstimulation of the immune system by cytokines which may lead to autoimmune diseases. Other neurological implications such as hypoxia, anosmia, dysgeusia, meningitis, encephalitis, and seizures are important symptoms presented clinically in COVID-19 patients with or without the common symptoms of the disease. Further, patients with higher severity of the SARS-CoV-2 infection are also at risk of retaining some neurological complications in the long-run. Treatment of such severe hyperinflammatory conditions will also be discussed, as well as the risks they may pose to the progression of the disease. For this review, articles pertaining information on the neurological manifestation of SARS-CoV-2 infection were gathered from PubMed and Google Scholar using the search keywords "SARS-CoV-2", "COVID-19", and "neurological dysfunction". The findings of the search were filtered, and relevant information were included.
\end{abstract}

Keywords: SARS-CoV-2; COVID-19; neurological manifestations; neurogenic; cytokine storm.

\section{INTRODUCTION}

The coronavirus disease 2019 (COVID-19), transmitted by the severe acute respiratory syndrome coronavirus 2 (SARS-CoV-2), has taken over the world by storm ever since its first reported incidence in Wuhan, China in December 2019, masked as a pneumonia outbreak (Allam, 2020; WHO, 2021). After unravelling its structure, scientists realized that coronaviruses that were known to cause mild infections and the common cold has evolved through genomic recombination and circulation as well as mutation in humans before emerging as its high virulence form, as the viral structure was found to resemble a combination of several known strains (Junejo et al., 2020; Li et al., 2020b).

SARS-CoV-2 is a novel betacoronavirus, one of the two genera of coronaviruses capable of affecting humans - the other being alphacoronaviruses - and the virus unsurprisingly came with flu-like features as symptoms, including high fever, cough, fatigue, and respiratory symptoms like shortness of breath (Zhang et al., 2018). Though, neurological manifestations became more apparent as consistent signs of smell and taste impairments, stroke, encephalopathy, meningitis, and seizures have been reported over the past year around the world (Koh et al., 2020; Mao et al., 2020; Moro et al., 2020). Early speculation on the possible neurological effects of COVID-19 on the nervous system anticipated its entry into the central nervous system (CNS) primarily, with in vitro results pointing towards the presence of virus in the cerebral spinal fluid (CSF), in addition to the brain being an organ vulnerable to viral infection in general, including influenza, measles, and HIV type-1 (Michalicová et al., 2017). Other betacoronaviruses epidemics which have caused considerable impacts in public health in the past including the 2003 SARS-CoV-1 outbreak and the 2012 Middle East Respiratory Syndrome (MERS) outbreak also recorded various overlapping neurological complications, though rare (Michalicová et al., 2017). This had raised comparison on their similarities with the current COVID-19 to cause nervous system dysfunction in both the peripheral and central branch (Algahtani et al., 2016; Zegarra-Valdivia 
et al., 2020). Researchers have hypothesized the possible pathophysiological routes of entry of the virus from clinical data and knowledge from the previous outbreaks.

Thus, the aim of this review is to highlight the effect of SARS-Cov-2 on the neurological wellbeing and its pathophysiology in central and peripheral nervous system invasion to further understand the emerging neurological symptoms reported in current literature. Possible impacts and risks of the current treatment of the disease as well as the future outlook of the disease in the nervous system will also be discussed to prepare the healthcare sector as the pandemic progresses over time.

\section{Role of ACE2 in SARS-CoV-2 nervous system invasion}

The angiotensin-converting enzyme 2 (ACE2) is a specific functional receptor for the SARS-CoV-2 virus and entry of the virus is largely dependent on but not exclusively due to the binding of this receptor (Nikbakht et al., 2020). A spike glycoprotein, the $S$ protein, on the viral envelope of SARSCoV-2 binds to the ACE2 receptors on the membrane of host cells to permit its entry into target host cells. The $S$ protein on the surface of SARS-CoV-2 is found to have an $80 \%$ similarity to one on SARS-CoV-1, which enters target cells through the same pathway (Walls et al., 2020). ACE2 facilitates conversion of angiotensin II to angiotensin (1-7), and as ACE2 is downregulated, higher levels of angiotensin II are produced which is associated with increased viral load along with oxidative processes that promote brain degeneration (Xia \& Lazartigues, 2010). Experiments on human ACE2 (hACE2) mice showed that they were successfully infected by SARSCoV-2 while wild-type mice did not take in the virus, confirming the direct relationship between ACE2 expression and viral entry into target cells (Bao et al., 2020). The A2a clade of SARS-CoV-2 is the dominant strain in India with 12 actively infectious strains in the continent being under that category, and its high virulence was found to be owing to a variant of the $S$ protein which have higher affinity to the ACE2 receptors due to the D614G mutation (Muttineni et al., 2021; Ozono et al., 2021; Sarkar et al., 2021).

Among the wide distribution of ACE2 in epithelial tissues and lung alveolar type II cells, its presence in the oral and nasal cavity, nasopharynx, glial and neuronal cells of the brainstem in areas that regulate cardiovascular and respiratory function also provides answers to the pathogenesis of SARS-CoV-2 into the nervous system (Xia \& Lazartigues, 2010). On the contrary, Hamming et al. (2004) found the lack of the ACE2 receptor in the epithelia of the upper respiratory tract, which did not agree with many other studies that reported otherwise. Li et al. (2020a) found that expression of ACE2 in the brain is positively associated with the response of immune system markers such as CD8+ T cell levels and interferon (IFN) levels, indicating its involvement in severe COVID-19 progression.

\section{Neurological complications from COVID-19}

\section{Pathophysiology}

Direct nervous system invasion

Direct penetration of the brain by SARS-CoV-2 is either by axonal transport through the neurogenic route or by the blood brain barrier (BBB) through the hematogenous route (Iadecola et al., 2020). The virus can enter the central nervous system retrogradely along the specific peripheral nerves according to the location in which the virus was exposed in the body, with the most common one being the olfactory nerve fibres, with a number of cases reporting COVID-19 patients suffering from smell impairment or anosmia (Altundag et al., 2020; ladecola et al., 2020; Mao et al., 2020). The brainstem was reported to be found in high incidence of the SARS-CoV and MERS-CoV from in vitro animal studies, suggesting it to be the terminus for this route of infection (Li et al., 2020c). The trigeminal nerve and vagus nerves are also proposed to be possible routes of entry of SARS-CoV-2 (Bougakov et al., 2020; Cataldi et al., 2020). The vagus nerves are a part of the General Visceral Afferent (GVA) nerve fibres which are responsible for innervating parts of the nasal cavity and soft palate in addition to the trachea and lungs, which synapses in the spinal trigeminal nerve in the head (Snyder \& Bartoshuk, 2016). Since the sense of taste is a coupled interaction between the olfactory and trigeminal systems, this pathway of SARS-CoV-2 transmission could be a contributing factor to the high number of COVID-19 patients presenting with symptoms of anosmia and dysgeusia.

The hematogenous route is a common route of entry for viruses that penetrate the brain, especially for coronaviruses including murine hepatitis virus (MHV), which was found from animal model studies to be countered by a heavy immune-mediated response in its acute stage and may affect the persistence of the virus long-term in the CNS (Bergmann et al., 2006). Blood endothelial cells stationed among the tight junctions of the BBB act as the first line of defence when it comes to protecting the brain from invading pathogens, whereas its penetration would risk infection of the cellular makeup of the CNS, including astrocytes and pericytes (McGavern \& Kang, 2011). The virus directly infects the brain by passing through the BBB, penetrating across the endothelial cells or hijacking peripheral blood cells consisting mainly of macrophages or monocytes located in the airway, then transmigrating to the brain via the bloodstream (Ding et al., 2014). The presence of ACE2 receptors in the brain endothelial may be a contributing factor in neurovascular damage in patients (Nath, 2020).

\section{Indirect nervous system invasion}

The indirect infiltration of the CNS can be seen as a progression from innate immunity activation to systemic inflammation which is yet another factor contributing to the damage of the BBB, where SARS-CoV viruses in the past have been found to induce powerful cytokine reactions as a result of local replication of the virus following infiltration through direct routes (Whittaker et al., 2020). A "cytokine storm" may develop in patients with severe infection when the viral load breaches the body's immunity, releasing an excessive wave of cytokines which is evident in increased levels of chemokines, interleukin (IL)-6, IL-8, IFN- $\gamma$ and tumour necrosis factor (TNF) (Hojyo et al., 2020). This phenomenon is similar to the avian H5N1 influenza, which was when the term first made its way into mainstream media. Due to the increased vascular permeability and edema, the widespread inflammation eventually causes organ damage, a major cause of organ failure and death in COVID-19 patients, accompanying acute respiratory distress syndrome (ARDS) (Chen et al., 2020; Zhao et al., 2020).

Guillain-Barré Syndrome (GBS) is an autoimmune disorder that attacks healthy nerve cells and it is an increasingly common clinical presentation in COVID-19 patients, with a combined case review reporting 9 out of 11 cases having onset of the disease only 5 to 11 days postdiagnosis (Zhao et al., 2020). The clinical features presented were quite consistent, with weakness in the lower limbs compared to the upper limbs, and loss of deep tendon reflexes and other sensory weakness which varies according to individuals (Whittaker et al., 2020). A case report from March 2020 suggested the cytokine storm syndrome is tied to 
acute necrotizing encephalopathy, also seen in COVID-19 patients who developed GBS post-infection (Fotuhi et al., 2020).

Hypoxia is a recurrent feature in COVID-19 patients due to pulmonary insufficiency, and the resultant blood clots in the brain as seen in brain scans further blocks oxygen supply to neural tissues (Fotuhi et al., 2020). The key player in the cellular mechanism of hypoxia is mediated by the hypoxia-inducible factor 1 (HIF-1), where its activation requires a subunit, HIF-1 $\alpha$ (Reyes et al., 2020). Under hypoxic environments, angiotensin $\mathrm{II}$ is increased which cause a downregulation in ACE2 protein, whereas when angiotensin II is inhibited, ACE2 protein expression was not seen to reduce in the overexpression of HIF-1 $\alpha$, suggesting that hypoxia is not to be overlooked as a determinant of SARSCoV-2 infection severity (Zhang et al., 2009; Reyes et al., 2020). The pathophysiology of neurological complications from COVID-19 is illustrated in Figure 1.

\section{Neurological sequelae of COVID-19}

As mentioned previously, neurological manifestation following COVID-19 infection varies according to the route of entry of the SARS-CoV-2 virus, distribution of ACE2 receptors, and the degree of immune system activation which follows. These factors contribute to the consequences of the cytokine storm. The pathophysiology of the virus serves to justify the clinical manifestation of neurological origin, where in this context includes the presentation of loss of smell and taste, meningitis, encephalitis, myelitis, seizure, and ischemic stroke.
Loss of smell and taste

Loss of smell and taste are the most common peripheral nervous system symptoms which were consistently presented early during infection, emerging from 0 to 3 days of confirmation (Naz et al., 2020). Most patients recover after 1 to 3 weeks, as reported by a study done in an Egyptian hospital $(n=65)$, where more than $80 \%$ patients experienced partial or complete loss of smell and taste (Al-Zaidi \& Badr, 2020). However, another study done in China $(n=196)$ through telephone survey found that more than half of the patients out of $19.9 \%$ with reported taste and smell dysfunction experienced a recovery period of 4 weeks or more (Lv et al., 2020). A cross-sectional study in Singapore further confirmed that Caucasians are found to be more susceptible to such disorders (Tham et al., 2021). Nonetheless, evidence of having such impairments as the determining symptoms of COVID19 infection is scarce, with most being accompanied by cough, fever, and sore throat. Mild anosmia contributed to a large proportion of COVID-19 patients, followed by a complete and moderate degree of severity, with the female population and middle-aged population more at risk of developing it along with the loss of taste (Carrillo-Larco \& Altez-Fernandez, 2020; Meng et al., 2020).

Taste impairment in this case includes the partial or complete loss of taste, hypogeusia and ageusia respectively, in addition to altered sense of taste, dysgeusia which varies among patients, and these symptoms were reported in a majority of patients early or before confirmation of the disease, with the latter ranging from less than a week to two weeks in $84.5 \%$ of patients in the category (Al-Zaidi \&

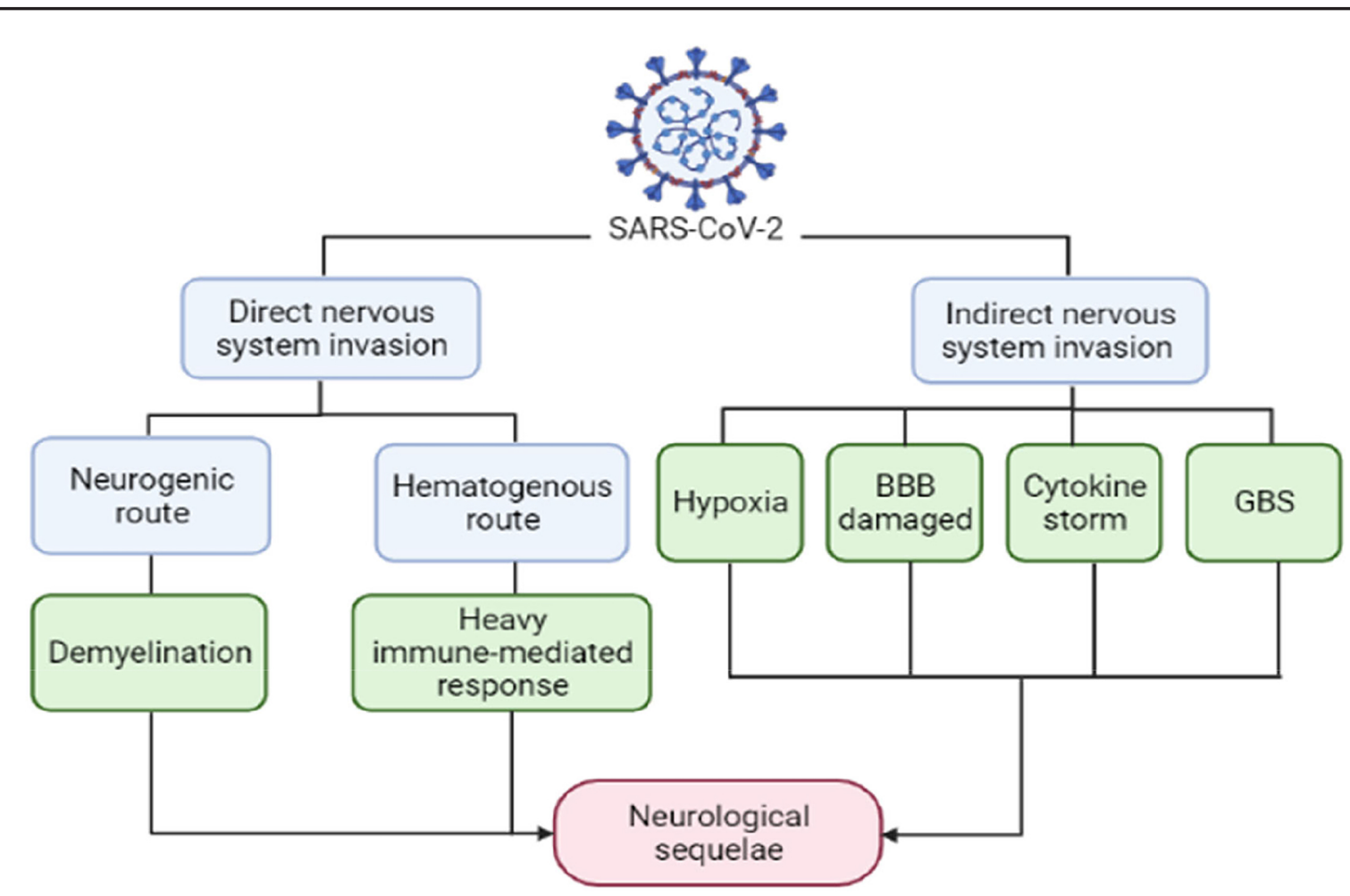

Created in BioRender.com bio

Figure 1. Pathophysiology of neurological complications from COVID-19. BBB: Blood brain barrier; GBS: Guillain-Barré Syndrome. [This figure is created in BioRender.com.] 
Badr, 2020). Since ACE2 receptors are also abundant in the olfactory and gustatory tract including the nasal epithelium and oral cavity, the mechanism behind the onset of dysgeusia could be the affinity of the SARS-CoV-2 virus on the ACE2 receptors in the relevant route of entry through the facial orifices (Sato et al., 2021).

\section{Meningitis}

Meningitis was often mistaken for a separate onset rather than a symptom for COVID-19, especially since it was rare to be the sole presenting symptom of the infection. The first recorded case of meningitis being a symptom of COVID-19 was in Japan in February 2020 (Moriguchi et al., 2020). The underlying cause could be due to the effects of cytokine storm, which, if persists, have brain-damaging effects including rupture of arteries in the meninges, making the brain even more susceptible to viral entry once it is exposed, as brain endothelial cells are known to be rich in ACE2 receptors (Tisoncik et al., 2012). Autopsy results of SARS patients revealed inflamed meninges as a frequent occurrence that contribute to death, though in terms of COVID-19, Moriguchi et al. was one of the few articles to report SARS-CoV-2 findings in CSF in two patients who presented with meningitis and encephalitis (Zhang et al., 2003; Moriguchi et al., 2020).

\section{Encephalitis}

Encephalitis is one of the other neurological sequelae that may occur in later phases of COVID-19 disease course. The common symptoms of viral encephalitis include high fever, headache, vomiting, convulsions, and consciousness disorders (Ellul \& Solomon, 2018). The first case of viral encephalitis associated with COVID-19 was reported by Beijing Ditan Hospital in March 2020 (Xiang et al., 2020). Genome sequencing enables scientists to confirm the presence of SARS-CoV-2 in CSF of patients with COVID-19, providing new evidence to the theory of this virus' ability to damage the host's nervous system and cause viral encephalitis (Xiang et al., 2020). The first presumptive case of COVID-19 related acute necrotizing haemorrhagic encephalopathy was reported by Poyiadji et al. (2020), suggesting its onset to be due to BBB breakdown which demonstrates the potential of cytokine storm syndrome in severe COVID-19 patients. However, there was still a lack of evidence to confirm the effect of COVID-19 on the patients' nervous system were due to direct viral invasion, parainfectious autoimmune coagulopathy, or a combination (Umapathi et al., 2020). The pathogenesis of nervous system injury by COVID-19 was proposed in different pathways, such as blood circulation pathway, neuronal pathway, hypoxia injury, immune injury, and ACE2 (Wu et al., 2020b). The immune injury is referring to the development of systemic inflammatory response syndrome (SIRS) in the severe case of viral infections, which could be initiated by SARS-CoV-2 infection (Wu et al., 2020b). In addition, the viruses in the CNS are difficult to remove due to the lack of major histocompatibility complex (MHC) antigens in the CNS, resulting in the complete reliance on cytotoxic $T$ cells for virus elimination ( $\mathrm{Wu}$ et al., 2020b). The continued existence of the virus in the CNS may further attribute to the development of neurological damage.

\section{Myelitis}

Furthermore, myelitis is also clinically manifesting as one of the neurological deficits that involve a different degree of sensory, motor, and autonomic modalities in COVID-19 infections. Transverse myelitis is heterogeneous non- compressive myelopathy or known as spinal cord dysfunction due to inflammation (Chakraborty et al., 2020). A case of acute transverse myelitis (ATM) associated with COVID-19 infection was reported in a 59-year-old non-diabetic and nonhypertensive obese female in India (Chakraborty et al., 2020). In this case, the patient was showing acute-onset progressive ascending flaccid paraplegia on both lower limbs, together with urine retention, constipation and high fever (Chakraborty et al., 2020). The exact pathogenesis of ATM remains obscure; however, it is believed to be an immune-mediated response to SARS-CoV-2 virus infection (Chakraborty et al., 2020). Some similar symptoms such as leg pain, numbness, and weakness may direct to different neurological manifestations, such as the COVID-19 associated peripheral neuropathy (Bureau et al., 2020). Few reported cases of COVID-19 associated peripheral neuropathy were showing similar findings, in which maximal symptom at the onset with slow and progressive improvement and followed typical COVID-19 respiratory symptoms (Abdelnour et al., 2020; Bureau et al., 2020). These suggested the likeliness of post-infectious immune-mediated neuropathy as one of the possible neurological implications in severe COVID-19 infections (Bureau et al., 2020).

\section{Seizure}

According to Emami et al. (2020), seizure was observed in COVID-19 patients regardless of gender or age and the infections may also trigger de novo seizures in patients without a history of epilepsy. Seizure was suggested to be a consequence of hypoxia, multiorgan failure, metabolic and electrolyte disarrangements, or even neuroinvasion or cerebral damage in COVID-19 patients (Asadi-Pooya, 2020; Emami et al., 2020). The COVID-19 infection tends to break down the integrity of the $\mathrm{BBB}$, resulting in brain homeostasis impairments which leads to neuronal cell death (Reynolds \& Mahajan, 2021). The BBB breakdown might cause the migration of immune cells and proteins, such as albumin, which can disrupt the osmotic balance in CNS and cause seizure (Rana \& Musto, 2018; Reynolds \& Mahajan, 2021). Seizure in COVID-19 can also be caused by an imbalance in ion channel function including an increase in excitatory neurotransmitters such as glutamate and aspartate, and a decrease in inhibitory gamma-aminobutyric acid (GABA) (Nikbakht et al., 2020). High fever of $40^{\circ} \mathrm{C}$ and above triggers the release of cytokines such as IL-1 13 , which is found in high amounts in the brains of deceased seizure patients (Whittaker et al., 2020). Fotuhi et al. (2020) proposed a progression of the neurological manifestation of COVID-19 infection in three stages, where at the end of each stage, there is a chance of recovery or progression of the disease towards symptoms of greater severity. Anosmia and dysgeusia make up the first stage, followed by strokes due to blood clots and damage in cranial and peripheral nerves, and lastly, delirium, encephalopathy, and seizures as brain injury worsen (Fotuhi et al., 2020).

\section{Ischemic stroke}

According to Ghannam et al. (2020), there were $48.8 \%$ of cerebrovascular incidents in COVID-19 patients with neurological involvement reported, while the majority (87.5\%) were ischemic stroke. The systemic response to COVID-19 infection resulting in coagulopathy and hypercoagulability, together with endothelial injury caused by the direct viral invasion, and venous stasis due to immobilization are all associated with cerebrovascular disease in COVID-19 patients (Qi et al., 2020). The formation of blood clots due to the robust immune response may lead to stroke due to 
arterial occlusion or venous thrombosis (Umapathi et al., 2004). Patients with SARS-CoV-2-induced stroke is common especially in older patients aged 70 and above, and higher mortality is seen in patients with severe COVID-19 respiratory symptoms and other underlying health conditions, which could be related to the heightened pro-inflammatory IL levels in elderly patients who suffered from delirium (Fridman et al., 2020). In a case series, the time at which patients developed ischaemic stroke varies from preconfirmation of the infection to 24 days after COVID-19 symptoms emerged (Beyrouti et al., 2020).

The neurological sequelae of COVID-19 are summarised in Table 1.

\section{Possible long-term complications of COVID-19}

Even though COVID-19 is still at its early stage of the pandemic and it is still too soon to know the long-term effects on the body, evidence from past coronavirus outbreaks like SARS and MERS can give an estimation on the future direction of the disease (Park et al., 2020). In 2009, patients of SARSCoV-1 were monitored 31 to 50 months after recovery and it was found that most of them suffered from either one or more neuropsychiatric conditions, which were obsessive compulsion disorder, depression, post-traumatic stress disorder, and panic disorders (Troyer et al., 2020). It is predicted that patients who survived severe symptoms of COVID-19 have a higher risk of developing neurocognitive complications as previously mentioned and demyelinating disorders similar to multiple sclerosis (MS) in the future. Cytokine storms have the ability to cause punctate strokes which may result in poor memory and attention, in addition to slowness in processing information for up to 8 months after recovery, therefore regular neurocognitive testing is recommended so that treatment can be given accordingly to patients who are affected by these effects (Helms et al., 2020). All the possible long-term neurological complications of COVID-19 are summarised in Table 2 .

\section{Post-COVID-19 Neurological Syndrome}

As the pandemic continues, more and more cases were studied and the long-term impact of the SARS-CoV-2 on the human brain was slowly uncovered, known as Post-COVID19 Neurological Syndrome (PCNS) (Wijeratne \& Crewther, 2020). The disease progression of COVID-19 causing the build-up of pro-inflammatory agents such as IFN- $\gamma, \mathrm{IL}-7$ and other cytokines is known to induce post-stroke depression (PSD) (Wijeratne \& Crewther, 2021). Thus, the symptoms of PCNS are similar to PSD, such as chronic fatigue, depression, apathy, persistent attention and cognitive problems. In view of the scale of global infection, PCNS is expected to affect a younger age group than PSD, and thus it possesses the potential to become a major health problem. Other prolonged symptoms such as muscle pain, dizziness, headaches, and anosmia were reported among large number of asymptomatic or very mildly symptomatic patients, highlighting the need for ongoing vigilance for PCNS (Goërtz et al., 2020).

\section{Neuropsychiatric symptoms}

In addition, COVID-19 infections have also possessed the potential of developing a post-viral syndrome, a sense of fatigue that arise for weeks to months after recovering from viral infection (Bureau et al., 2020). The likely neuropsychiatric symptoms of post-COVID-19 syndrome include chronic fatigue, diffuse myalgia, depression, headache, cognitive impairment, and sleep disturbances caused by neuroimmune exhaustion (Nalbandian et al., 2021). The proposed pathophysiology of these complications is associated with immune dysregulation, inflammation, microvascular thrombosis, iatrogenic effects of medications and psychosocial impacts of the infections (Nalbandian et al., 2021).

Table 1. Neurological sequelae of COVID-19

\begin{tabular}{|c|c|c|c|}
\hline Methods & Neurological sequelae & Limitations & References \\
\hline $\begin{array}{l}\text { Retrospective case series of } 65 \\
\text { admitted patients. }\end{array}$ & $\begin{array}{l}\text { Smell dysfunction appeared in } 89.23 \% \text { with or without } \\
\text { other symptoms of COVID-19. Taste dysfunction found } \\
\text { in } 83.08 \% \text { patients with other COVID-19 symptoms. }\end{array}$ & $\begin{array}{l}\text { Not specifically studied neuro- } \\
\text { logical manifestations. } \\
\text { No CSF studies. }\end{array}$ & $\begin{array}{l}\text { Al-Zaidi \& Badr, } \\
2020\end{array}$ \\
\hline Brain MRI and CSF analysis. & $\begin{array}{l}\text { A brain MRI suggesting the possibility of SARS-CoV- } 2 \\
\text { meningitis. Diagnosed with aseptic encephalitis with } \\
\text { SARS-CoV-2 RNA in CSF. }\end{array}$ & $\begin{array}{l}\text { Other related neurological mani- } \\
\text { festations were not studied. No } \\
\text { EEG studies. }\end{array}$ & $\begin{array}{l}\text { Moriguchi et } \\
\text { al., } 2020\end{array}$ \\
\hline CSF analysis & Viral encephalitis. & $\begin{array}{l}\text { Other related neurological mani- } \\
\text { festations were not studied. No } \\
\text { EEG studies. }\end{array}$ & $\begin{array}{l}\text { Xiang et al., } \\
2020\end{array}$ \\
\hline CT imaging and brain MRI. & Acute necrotizing hemorrhagic encephalopathy. & $\begin{array}{l}\text { Other related neurological mani- } \\
\text { festations were not studied. No } \\
\text { EEG studies. }\end{array}$ & $\begin{array}{l}\text { Poyiadji et al., } \\
2020\end{array}$ \\
\hline MRI and CSF analysis. & Acute transverse myelitis. & $\begin{array}{l}\text { RT-PCR for SARS-CoV- } 2 \text { was not } \\
\text { detected in patient's CSF. }\end{array}$ & $\begin{array}{l}\text { Chakraborty et } \\
\text { al., } 2020\end{array}$ \\
\hline $\begin{array}{l}\text { Retrospective case series of } 6147 \\
\text { admitted patients. }\end{array}$ & Seizure rate $0.08 \%$. & $\begin{array}{l}\text { CSF, brain imaging and EEG were } \\
\text { not studied in all patients. }\end{array}$ & Qi et al., 2020 \\
\hline $\begin{array}{l}\text { Systematic reviews and meta- } \\
\text { analyses. }\end{array}$ & $\begin{array}{l}48.8 \% \text { of the patients ( } n=40) \text { had cerebrovascular } \\
\text { insults, } 28 \%(n=23) \text { had neuromuscular disorders, and } \\
23 \% \text { of the patients }(n=19) \text { had encephalitis or } \\
\text { encephalopathy. Ischemic stroke in } 42.7 \% \text {. }\end{array}$ & - & $\begin{array}{l}\text { Emami et al., } \\
2020\end{array}$ \\
\hline
\end{tabular}


Table 2. Possible long-term neurological complications of COVID-19

\begin{tabular}{|c|c|c|c|}
\hline Neurological Complication & Symptoms & Mechanism & References \\
\hline $\begin{array}{l}\text { Post-COVID-19 neurological } \\
\text { syndrome }\end{array}$ & $\begin{array}{l}\text { Chronic fatigue, depression, apathy, persistent } \\
\text { attention, and cognitive problems }\end{array}$ & $\begin{array}{l}\text { Pro-inflammatory agents such as } \\
\text { IFN- } \gamma, \text { IL-7 and other cytokines } \\
\text { build-up }\end{array}$ & $\begin{array}{l}\text { Wijeratne \& } \\
\text { Crewther, } \\
2021\end{array}$ \\
\hline Neuropsychiatric symptoms & $\begin{array}{l}\text { Chronic fatigue, diffuse myalgia, depression, } \\
\text { headache, cognitive impairment, sleep disturbances, } \\
\text { post-traumatic stress disorder, and panic disorders }\end{array}$ & Neuroimmune exhaustion & $\begin{array}{l}\text { Nalbandian et } \\
\text { al., 2021; } \\
\text { Troyer et al., } \\
2020\end{array}$ \\
\hline $\begin{array}{l}\text { Neurodegeneration (Parkinson's } \\
\text { disease) }\end{array}$ & Movement disorders & $\begin{array}{l}\text { Accumulation of alpha-synuclein } \\
\text { in the brain }\end{array}$ & $\begin{array}{l}\text { Antonini et al., } \\
\text { 2020; Ferini- } \\
\text { Strambi \& } \\
\text { Salsone, } 2021\end{array}$ \\
\hline Post-infectious seizure & Seizure & Neuroinvasion or cerebral damage & $\begin{array}{l}\text { Kincaid et al., } \\
2021\end{array}$ \\
\hline $\begin{array}{l}\text { Complication of punctate } \\
\text { strokes }\end{array}$ & $\begin{array}{l}\text { Poor memory and attention, and slowness in } \\
\text { processing information }\end{array}$ & Cytokine storms & $\begin{array}{l}\text { Helms et al. } \\
2020\end{array}$ \\
\hline
\end{tabular}

\section{Neurological related disorders}

Further, neurological manifestations including encephalitis and stroke have a history of causing continuing consequences on the nervous system. There were few well-consolidated shreds of evidence linking COVID-19 to movement disorders, particularly for Parkinson's Disease (PD) (Antonini et al., 2020; Ferini-Strambi \& Salsone, 2021). Accumulation of alphasynuclein (aSyn), the main protein component of Lewy bodies in the brain was proposed in a model of neurodegeneration by SARS-CoV2 (Ferini-Strambi \& Salsone, 2021). These findings indicating the PD-neurodegeneration might be induced by SARS-CoV2 by accelerating ageing in the brain (Ferini-Strambi \& Salsone, 2021). Long-term follow up can be done utilizing neuroimaging on the brainstem to evaluate the integrity of the glial and neuronal cells as the brainstem is most susceptible to the virus in the neuronal route of entry and could be targeted for demyelination after recovery (Ogier et al., 2020). Comfortingly, most of the new-onset seizures in COVID-19 patients were believed to be acute symptomatic seizures, thus, long-term antiseizure medication (ASM) treatment is generally not required, unless a subsequent seizure occurs (Park et al., 2020). Considering the scale of the COVID-19 pandemic, a change in the social norms in years following the pandemic would be expected, which should be taken seriously to prevent the repercussions of excessive burden to fall onto the hands of the medical sector.

\section{Challenges of COVID-19 neurological manifestations treatment}

Early treatment of COVID-19 infection focused on the lower respiratory tract as the primary target of SARS-CoV-2 were the lungs. As severe symptoms of COVID-19 became more prevalent and consistent with increasing death tolls as well as evidence pointing towards immune system failure as the predominant cause, studies were done in search of suitable treatments to help improve such symptoms (Gibson et al., 2020; Wu et al., 2020a). Critical health conditions in need of intensive care involving immune system malfunctioning, which in the case of severe COVID-19 infection were hyperinflammation that subsequently leads to multiorgan failure, are a challenging feat in terms of treatment, and the mortality rate was largely caused by such complications (Ragab et al., 2020).
Hyperinflammation is suggested to be tightly associated with several neurological deficits, such as transverse myelitis, encephalopathy, PCNS, or even stroke. Thus, immunosuppressive agents are arguably the most logical approach to patients with hyperinflammation. Corticosteroids are clinically proven to suppress pro-inflammatory cytokine production and were widely used in therapy during the SARS and MERS outbreaks, which justifies its application in the current pandemic (Lee et al., 2020). However, the argument is that long-term treatment of COVID-19 with glucocorticoids of more than 10 days could result in a hypercoagulation state resulted in thrombosis, as shown in a 5-day duration treatment of dexamethasone that had triggered an increase in clotting factors and fibrinogen in vivo (Brotman et al., 2006). Prolonged anti-inflammatory effects could inhibit the future anti-viral capacity of the patient's body which invites recurrence of the infection due to delayed viral clearance, with findings suggesting the brain as a reservoir for dormant viral particles (Mehta et al., 2020; Ritchie \& Singanayagam, 2020). Neurological complications were also reported with the use of intravenous corticosteroids for ARDS and this outcome may prolong the infection of COVID-19 in addition to burdening the already compromised nervous system (Steinberg et al., 2006).

Most of the treatments for COVID-19 associated neurological manifestations available now are pragmatically and symptomatically with an emphasis on holistic support. Nevertheless, the outcomes of the treatment might be limited and influenced by many factors. For instance, in COVID-19 patients who developed seizures, or COVID-19 in patients with epilepsy (PWE), drug-drug interactions between ASMs and anti-COVID therapies may occur and pose a great challenge (Umapathi et al., 2004). Adjustment to ASMs may be required for patients with severe COVID-19 infection, in which cardiac, hepatic, or renal impairments may have arisen (Umapathi et al., 2004). Furthermore, the co-administration of these two groups of drugs may carry an added risk to cardiac conduction abnormalities, attributed to the adverse effects of both groups of therapies (Umapathi et al., 2004; Auerbach et al., 2018). 


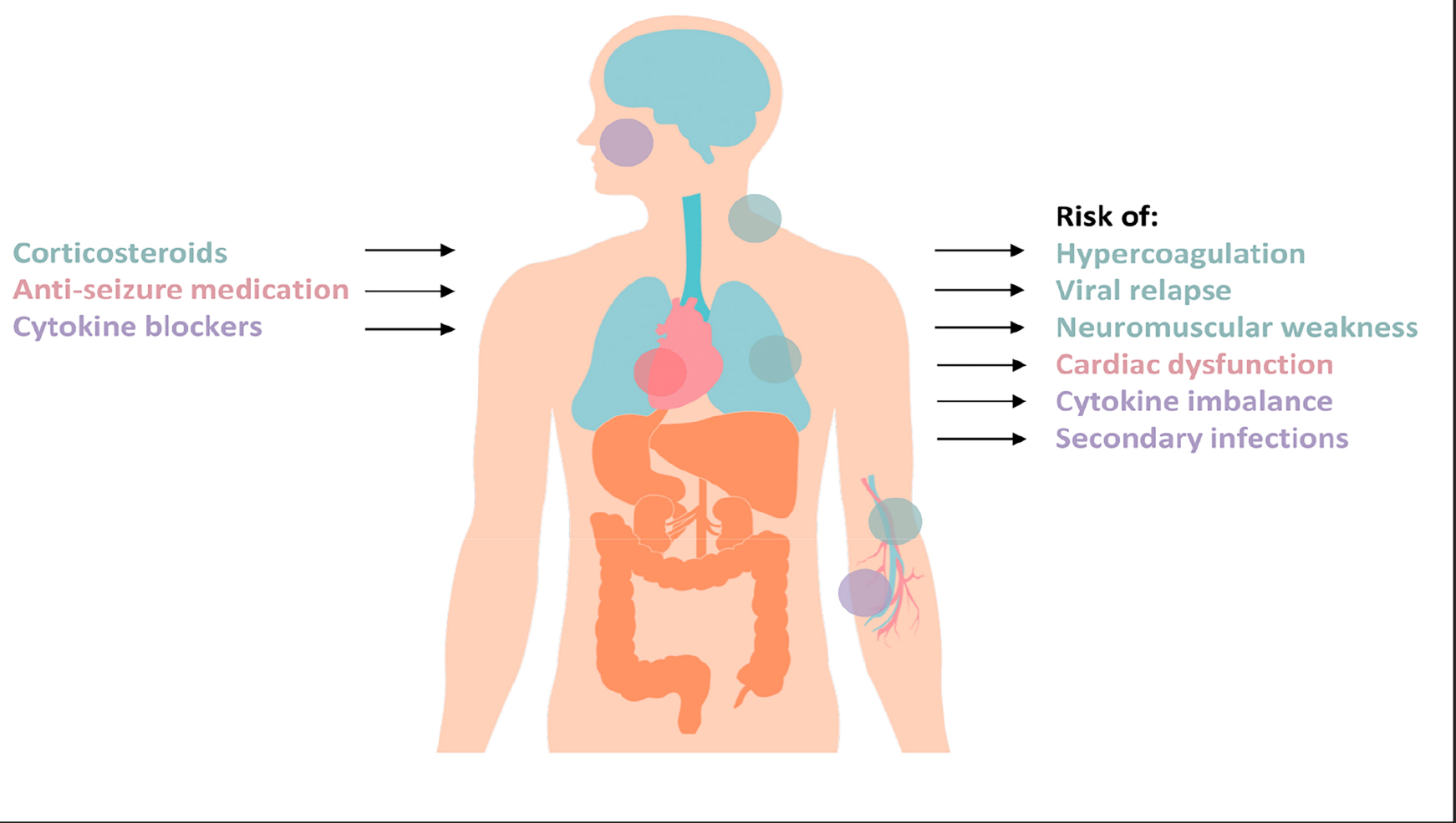

Figure 2. Possible complications from COVID-19 treatment for neurological manifestation. Administration of immunosuppressing corticosteroids to treat pro-inflammatory cytokine production may result in hypercoagulation, reinfection from dormant viral particles in the brain, and neuromuscular weakness. Anti-seizure medication in combination with COVID-19 therapy may result in cardiac dysfunction. Cytokine blockers, most commonly IL-6 blockers, possibly leads to cytokine imbalance in the body from the natural counterbalancing by other pro-inflammatory mediators, increasing risk of secondary infections.

The severity of the autoimmune attacks could lead to various neurological complications, including seizure and PCNS, which may be from the overexpression of a single cytokine, primarily IL-6, or from the concerted effect of several inflammatory mediators (Lu et al., 2020). All in all, an early detection of SARS-CoV-2-afflicted pathological inflammation would give an advantage of a better recovery and lower chance of relapse of the disease, as seen in results obtained by several studies which administered the treatment at different stages (Benucci et al., 2020; Radbel et al., 2020). To combat the devastating effects of an inflammatory storm and to prevent mortality, researchers seek the efficacy in cytokine blockers and neutralizers. $\mathrm{Xu}$ and colleagues found that treatment using an IL- 6 blocker, tocilizumab, on patients with severe COVID-19 infection had improved clinical symptoms in $75 \%$ of the patients over the span of 5 days (Xu et al., 2020). Other randomised clinical trials utilizing IL-6 blocking or neutralizing treatments also gave promising results (Gritti et al., 2020; Lu et al., 2020). Unfortunately, there is not much evidence on the interaction between cytokine blockers co-treated with immunomodulatory drugs for patients with other underlying comorbidities to evaluate the suitability and further understand COVID-19 pathophysiology in patients with neurological implications, though it is proposed that the blockage of one or several cytokines may cause a backfiring effect due to the body's natural response to compensate with other pro-inflammatory mediators, increasing the risk of viral infection other than SARS-CoV-2 (Liu et al., 2020). Figure 2 summarises the possible complications from COVID-19 treatments for neurological manifestation.

\section{Future Direction}

The pathways by which SARS-CoV-2 enter and damage the nervous system in addition to the clinical presentation of neurological implications ranging from mild to severe as highlighted previously could contribute to determining the optimal combination of drugs for COVID-19 patients with varying neurological symptoms or underlying neurological comorbidities. Therefore, a suitable approach to proceed from the current research is to run clinical trials to justify the repurposing of existing drugs in treating novel conditions. Additionally, the neurological aftermath of a deadly outbreak as seen in patients of SARS and MERS in the past should be a calling for medical professionals to monitor the longterm wellbeing of patients to contribute toward a more specialised treatment regime for post-recovery patients to avoid a devastating post-COVID-19 health crisis in the future.

\section{Concluding remarks}

To conclude, both direct and indirect penetration of SARSCoV-2 virus are capable of manifesting into neurological complications throughout onset of COVID-19 disease, be it adverse or mild. In this article, six of such manifestations which were prominently reported in cases all around the world were highlighted, demonstrating the scope of neurological implications caused by the virus in terms of severity and complexity. With that, the possible long-term effects imposed on the physical and mental wellbeing of patients after COVID-19 recovery were also delved into, which were found to be tied to underlying neurological disorders. The use of certain medication was found to be contradictory to other treatment options or health issues contributed by 
SARS-CoV-2 infection, suggesting the need for a safe and proper treatment regime to be discovered.

With the growing clinical evidence that the neurological implications shown by SARS-CoV-2 infected patients might not be chance, medical practitioners are urged to be more diligent in realizing the first signs of neurological symptoms which may be strong indications of the severity of the infection. Epidemiologists have since agreed that the virus is to stay as a global population for many years to come. Therefore, healthcare decision-makers should be mindful of the future neurological impacts that COVID-19 might have on patients in the upcoming years and be prepared to combat it even after the pandemic.

\section{Conflict of Interest}

The authors declare that there is no conflict of interest.

\section{REFERENCES}

Abdelnour, L., Eltahir Abdalla, M. \& Babiker, S. (2020). COVID 19 infection presenting as motor peripheral neuropathy. Journal of the Formosan Medical Association 119: 1119-1120. https://doi.org/10.1016/j.jfma.2020.04.024

Al-Zaidi, H.M.H. \& Badr, H.M. (2020). Incidence and recovery of smell and taste dysfunction in COVID-19 positive patients. The Egyptian Journal of Otolaryngology 36: 47. https://doi.org/10.1186/s43163-020-00050-0

Algahtani, H., Subahi, A. \& Shirah, B. (2016). Neurological complications of Middle East Respiratory Syndrome Coronavirus: A report of two cases and review of the literature. Case Reports in Neurological Medicine 2016: 3502683. https://doi.org/10.1155/2016/3502683

Allam, Z. (2020). Chapter 1: The First 50 days of COVID-19: A detailed chronological timeline and extensive review of literature documenting the pandemic. In: Surveying the Covid-19 Pandemic and its Implications, Allam, Z. (editor). Armsterdam: Elsevier Inc, pp. 1-7. https://doi.org/10.1016/ b978-0-12-824313-8.00001-2

Altundag, A., Saatci, O., Sanli, D.E.T., Duz, O.A., Sanli, A.N., Olmuscelik, O., Temirbekov, D., Kandemirli, S.G. \& Karaaltin, A.B. (2020). The temporal course of COVID-19 anosmia and relation to other clinical symptoms. European Archives of Oto-Rhino-Laryngology 278: 1891-1897. https://doi.org/10.1007/s00405-020-06496-5

Antonini, A., Leta, V., Teo, J. \& Chaudhuri, K.R. (2020). Outcome of Parkinson's disease patients affected by COVID-19. Movement Disorders 35: 905-908. https://doi.org/10.1002/ mds.28104

Asadi-Pooya, A.A. (2020). Seizures associated with coronavirus infections. Seizure 79: 49-52. https://doi.org/10.1016/ j.seizure.2020.05.005

Auerbach, D.S., Biton, Y., Polonsky, B., McNitt, S., Gross, R.A., Dirksen, R.T. \& Moss, A.J. (2018). Risk of cardiac events in Long QT syndrome patients when taking antiseizure medications. Translational Research 191: 81-92.e7. https:// doi.org/10.1016/j.trsl.2017.10.002

Bao, L., Deng, W., Huang, B., Gao, H., Liu, J., Ren, L., Wei, Q., Yu, P., Xu, Y., Qi, F. et al. (2020). The pathogenicity of SARS-CoV2 in hACE2 transgenic mice. Nature 583: 830-833. https:// doi.org/10.1038/s41586-020-2312-y

Benucci, M., Giannasi, G., Cecchini, P., Gobbi, F.L., Damiani, A., Grossi, V., Infantino, M. \& Manfredi, M. (2020). COVID19 pneumonia treated with Sarilumab: A clinical series of eight patients. Journal of Medical Virology 92: 2368-2370. https://doi.org/10.1002/jmv.26062
Bergmann, C.C., Lane, T.E. \& Stohlman, S.A. (2006). Coronavirus infection of the central nervous system: Host-virus standoff. Nature Reviews Microbiology 4: 121-132. https://doi.org/ 10.1038/nrmicro1343

Beyrouti, R., Adams, M.E., Benjamin, L., Cohen, H., Farmer, S.F., Goh, Y.Y., Humphries, F., Jäger, H.R., Losseff, N.A., Perry, R.J. et al. (2020). Characteristics of ischaemic stroke associated with COVID-19. Journal of Neurology, Neurosurgery and Psychiatry 91: 889-891. https://doi.org/10.1136/jnnp2020-323586

Bougakov, D., Podell, K. \& Goldberg, E. (2020). Multiple neuroinvasive pathways in COVID-19. Molecular Neurobiology 58: 564-575. https://doi.org/10.1007/s12035-02002152-5

Brotman, D.J., Girod, J.P., Posch, A., Jani, J.T., Patel, J.V., Gupta, M., Lip, G.Y.H., Reddy, S. \& Kickler, T.S. (2006). Effects of short-term glucocorticoids on hemostatic factors in healthy volunteers. Thrombosis Research 118: 247-252. https://doi.org/10.1016/j.thromres.2005.06.006

Bureau, B.L., Obeidat, A., Dhariwal, M.S. \& Jha, P. (2020). Peripheral Neuropathy as a Complication of SARS-Cov-2. Cureus 12: e11452. https://doi.org/10.7759/cureus.11452

Carrillo-Larco, R.M. \& Altez-Fernandez, C. (2020). Anosmia and dysgeusia in COVID-19: A systematic review. Wellcome Open Research 5: 94. https://doi.org/10.12688/wellcome openres.15917.1

Cataldi, M., Pignataro, G. \& Taglialatela, M. (2020). Neurobiology of coronaviruses: Potential relevance for COVID19. Neurobiology of Disease 143: 105007. https://doi.org/ 10.1016/j.nbd.2020.105007

Chakraborty, U., Chandra, A., Ray, A.K. \& Biswas, P. (2020). COVID-19-associated acute transverse myelitis: A rare entity. BMJ Case Reports 13: 238668. https://doi.org/10.1136/ bcr-2020-238668

Chen, G., Wu, D., Guo, W., Cao, Y., Huang, D., Wang, H., Wang, T., Zhang, X., Chen, H., Yu, H. et al. (2020). Clinical and immunological features of severe and moderate coronavirus disease 2019. Journal of Clinical Investigation 130: 2620-2629. https://doi.org/10.1172/JCI137244

Ding, H., Sagar, V., Agudelo, M., Pilakka-Kanthikeel, S., Atluri, V.S.R., Raymond, A., Samikkannu, T. \& Nair, M.P. (2014). Enhanced blood-brain barrier transmigration using a novel transferrin embedded fluorescent magnetoliposome nanoformulation. Nanotechnology 25: 055101. https://doi.org/10.1088/0957-4484/25/5/055101

Ellul, M. \& Solomon, T. (2018). Acute encephalitis - diagnosis and management. Clinical Medicine, Journal of the Royal College of Physicians of London 18: 155-159. https://doi.org/ 10.7861/clinmedicine.18-2-155

Emami, A., Fadakar, N., Akbari, A., Lotfi, M., Farazdaghi, M., Javanmardi, F., Rezaei, T. \& Asadi-Pooya, A.A. (2020). Seizure in patients with COVID-19. Neurological Sciences 41: 3057-3061. https://doi.org/10.1007/s10072-020-04731-9

Ferini-Strambi, L. \& Salsone, M. (2021). COVID-19 and neurological disorders: are neurodegenerative or neuroimmunological diseases more vulnerable? Journal of Neurology 268: 409-419. https://doi.org/10.1007/s00415-02010070-8

Fotuhi, M., Mian, A., Meysami, S. \& Raji, C.A. (2020). Neurobiology of COVID-19. Journal of Alzheimer's Disease 76: 3-19. https://doi.org/10.3233/JAD-200581

Fridman, S., Bres Bullrich, M., Jimenez-Ruiz, A., Costantini, P., Shah, P., Just, C., Vela-Duarte, D., Linfante, I., Sharifi-Razavi, A., Karimi, N. et al. (2020). Stroke risk, phenotypes, and death in COVID-19: Systematic review and newly reported cases. Neurology 95: e3373-e3385. https://doi.org/10.1212/ WNL.0000000000010851 
Ghannam, M., Alshaer, Q., Al-Chalabi, M., Zakarna, L., Robertson, J. \& Manousakis, G. (2020). Neurological involvement of coronavirus disease 2019: a systematic review. Journal of Neurology 267: 3135-3153. https://doi.org/ 10.1007/s00415-020-09990-2

Gibson, P.G., Qin, L. \& Puah, S.H. (2020). COVID-19 acute respiratory distress syndrome (ARDS): clinical features and differences from typical pre-COVID-19 ARDS. Medical Journal of Australia 213: 54-56.e1. https://doi.org/10.5694/ mja2.50674

Goërtz, Y.M.J., Van Herck, M., Delbressine, J.M., Vaes, A.W., Meys, R., Machado, F.V.C., Houben-Wilke, S., Burtin, C., Posthuma, R., Franssen, F.M.E. et al. (2020). Persistent symptoms 3 months after a SARS-CoV-2 infection: the postCOVID-19 syndrome? ERJ Open Research 6: 00542-02020. https://doi.org/10.1183/23120541.00542-2020

Gritti, G., Raimondi, F., Ripamonti, D., Riva, I., Landi, F., Alborghetti, L., Frigeni, M., Damiani, M., Micò, C., Fagiuoli, S. et al. (2020). IL-6 signalling pathway inactivation with siltuximab in patients with COVID-19 respiratory failure: An observational cohort study. medRxiv 20048561. [Preprint]. https://doi.org/10.1101/2020.04.01.20048561

Hamming, I., Timens, W., Bulthuis, M.L.C., Lely, A.T., Navis, G.J. \& van Goor, H. (2004). Tissue distribution of ACE2 protein, the functional receptor for SARS coronavirus. A first step in understanding SARS pathogenesis. The Journal of Pathology 203: 631-637. https://doi.org/10.1002/path.1570

Helms, J., Kremer, S., Merdji, H., Clere-Jehl, R., Schenck, M., Kummerlen, C., Collange, O., Boulay, C., Fafi-Kremer, S., Ohana, M. et al. (2020). Neurologic features in severe SARSCoV-2 infection. New England Journal of Medicine 382: 22682270. https://doi.org/10.1056/nejmc2008597

Hojyo, S., Uchida, M., Tanaka, K., Hasebe, R., Tanaka, Y., Murakami, M. \& Hirano, T. (2020). How COVID-19 induces cytokine storm with high mortality. Inflammation and Regeneration 40: 37. https://doi.org/10.1186/s41232-02000146-3

ladecola, C., Anrather, J. \& Kamel, H. (2020). Effects of COVID19 on the nervous system. Cell 183: 16-27.e1. https://doi. org/10.1016/j.cell.2020.08.028

Junejo, Y., Ozaslan, M., Safdar, M., Khailany, R.A., Rehman, S.U., Yousaf, W. \& Khan, M.A. (2020). Novel SARS-CoV-2/ COVID-19: Origin, pathogenesis, genes and genetic variations, immune responses and phylogenetic analysis. Gene Reports 20: 100752. https://doi.org/10.1016/j.genrep. 2020.100752

Kincaid, K.J., Kung, J.C., Senetar, A.J., Mendoza, D., Bonnin, D.A., Purtlebaugh, W.L., Cabatbat, R.M., Dickens, R., Echevarria, F.D., Kariyawasam, V. et al. (2021). Post-COVID seizure: A new feature of "long-COVID." eNeurologicalSci 23: 100340. https://doi.org/10.1016/J.ENSCI.2021.100340

Koh, J.S., De Silva, D.A., Quek, A.M.L., Chiew, H.J., Tu, T.M., Seet, C.Y.H., Hoe, R.H.M., Saini, M., Hui, A.C.F., Angon, J. et al. (2020). Neurology of COVID-19 in Singapore. Journal of the Neurological Sciences 418: 117118. https://doi.org/10.1016/ j.jns.2020.117118

Lee, K.H., Yoon, S., Jeong, G.H., Kim, J.Y., Han, Y.J., Hong, S.H., Ryu, S., Kim, J.S., Lee, J.Y., Yang, J.W. et al. (2020). Efficacy of corticosteroids in patients with SARS, MERS and COVID19: A systematic review and meta-analysis. Journal of Clinical Medicine 9: 2392. https://doi.org/10.3390/jcm9082392

Li, M.Y., Li, L., Zhang, Y. \& Wang, X.S. (2020a). Expression of the SARS-CoV-2 cell receptor gene ACE2 in a wide variety of human tissues. Infectious Diseases of Poverty 9: 45. https:// doi.org/10.1186/s40249-020-00662-x
Li, X., Giorg, E.E., Marichannegowda, M.H., Foley, B., Xiao, C., Kong, X.P., Chen, Y., Gnanakaran, S., Korber, B. \& Gao, F. (2020b). Emergence of SARS-CoV-2 through recombination and strong purifying selection. Science Advances 6: eabb9153. https://doi.org/10.1126/sciadv.abb9153

Li, Y.C., Bai, W.Z. \& Hashikawa, T. (2020c). The neuroinvasive potential of SARS-CoV2 may play a role in the respiratory failure of COVID-19 patients. Journal of Medical Virology 92: 552-555. https://doi.org/10.1002/jmv.25728

Liu, Y., Zhang, C., Huang, F., Yang, Y., Wang, F., Yuan, J., Zhang, Z., Qin, Y., Li, X., Zhao, D. et al. (2020). Elevated plasma levels of selective cytokines in COVID-19 patients reflect viral load and lung injury. National Science Review 7: 10031011. https://doi.org/10.1093/NSR/NWAA037

Lu, L., Zhang, H., Zhan, M., Jiang, J., Yin, H., Dauphars, D.J., Li, S.Y., Li, Y. \& He, Y.W. (2020). Preventing mortality in COVID19 Patients: Which cytokine to target in a raging storm? Frontiers in Cell and Developmental Biology 8: 677. https:// doi.org/10.3389/fcell.2020.00677

Lv, H., Zhang, W., Zhu, Z., Xiong, Q., Xiang, R., Wang, Y., Shi, W., Deng, Z. \& Xu, Y. (2020). Prevalence and recovery time of olfactory and gustatory dysfunction in hospitalized patients with COVID-19 in Wuhan, China. International Journal of Infectious Diseases 100: 507-512. https://doi.org/ 10.1016/j.ijid.2020.09.039

Mao, L., Jin, H., Wang, M., Hu, Y., Chen, S., He, Q., Chang, J., Hong, C., Zhou, Y., Wang, D. et al. (2020). Neurologic manifestations of hospitalized patients with Coronavirus Disease 2019 in Wuhan, China. JAMA Neurology 77: 683690. https://doi.org/10.1001/jamaneurol.2020.1127

McGavern, D.B. \& Kang, S.S. (2011). Illuminating viral infections in the nervous system. Nature Reviews Immunology 11: 318-329. https://doi.org/10.1038/nri2971

Mehta, P., McAuley, D.F., Brown, M., Sanchez, E., Tattersall, R.S. \& Manson, J.J. (2020). COVID-19: consider cytokine storm syndromes and immunosuppression. The Lancet 395: 10331034. https://doi.org/10.1016/S0140-6736(20)30628-0

Meng, X., Deng, Y., Dai, Z. \& Meng, Z. (2020). COVID-19 and anosmia: A review based on up-to-date knowledge. American Journal of Otolaryngology - Head and Neck Medicine and Surgery 41: 102581. https://doi.org/10.1016/j.amjoto. 2020.102581

Michalicová, A., Bhide, K., Bhide, M. \& Kováè, A. (2017). How viruses infiltrate the central nervous system. Acta Virologica 61: 393-400. https://doi.org/10.4149/av_2017_401

Moriguchi, T., Harii, N., Goto, J., Harada, D., Sugawara, H., Takamino, J., Ueno, M., Sakata, H., Kondo, K., Myose, N. et al. (2020). A first case of meningitis/encephalitis associated with SARS-Coronavirus-2. International Journal of Infectious Diseases 94: 55-58. https://doi.org/10.1016/ j.ijid.2020.03.062

Moro, E., Priori, A., Beghi, E., Helbok, R., Campiglio, L., Bassetti, C.L., Bianchi, E., Maia, L.F., Ozturk, S., Cavallieri, F. et al. (2020). The international European Academy of Neurology survey on neurological symptoms in patients with COVID19 infection. European Journal of Neurology 27: 1727-1737. https://doi.org/10.1111/ene.14407

Muttineni, R., Kammili, N., Bingi, T.C., Rao M.R., Putty, K., Dholaniya, P.S., Puli, R.K., Pakalapati, S., Saritha, S., Shekar, K. et al. (2021). Clinical and whole genome characterization of SARS-CoV-2 in India. PLOS ONE 16: e0246173. https:// doi.org/10.1371/journal.pone.0246173

Nalbandian, A., Sehgal, K., Gupta, A., Madhavan, M.V., McGroder, C., Stevens, J.S., Cook, J.R., Nordvig, A.S., Shalev, D., Sehrawat, T.S. et al. (2021). Post-acute COVID-19 syndrome. Nature Medicine 27: 601-615. https://doi.org/ 10.1038/s41591-021-01283-z 
Nath, A. (2020). Neurologic complications of coronavirus infections. Neurology 94: 809-810. https://doi.org/10.1212/ WNL.0000000000009455

Naz, S., Hanif, M., Haider, M.A., Ali, M.J., Ahmed, M.U. \& Saleem, S. (2020). Meningitis as an initial presentation of COVID19: A case report. Frontiers in Public Health 8: 474. https:// doi.org/10.3389/fpubh.2020.00474

Nikbakht, F., Mohammadkhanizadeh, A. \& Mohammadi, E. (2020). How does the COVID-19 cause seizure and epilepsy in patients? The potential mechanisms. Multiple Sclerosis and Related Disorders 46: 102535. https://doi.org/ 10.1016/j.msard.2020.102535

Ogier, M., Andéol, G., Sagui, E. \& Dal Bo, G. (2020). How to detect and track chronic neurologic sequelae of COVID-19? Use of auditory brainstem responses and neuroimaging for long-term patient follow-up. Brain, Behavior, \& Immunity - Health 5: 100081. https://doi.org/ 10.1016/j.bbih.2020.100081

Ozono, S., Zhang, Y., Ode, H., Sano, K., Tan, T.S., Imai, K., Miyoshi, K., Kishigami, S., Ueno, T., Iwatani, Y. et al. (2021). SARSCoV-2 D614G spike mutation increases entry efficiency with enhanced ACE2-binding affinity. Nature Communications 12: 848. https://doi.org/10.1038/s41467-021-21118-2

Park, H.Y., Park, W.B., Lee, S.H., Kim, J.L., Lee, J.J., Lee, H. \& Shin, H.S. (2020). Posttraumatic stress disorder and depression of survivors 12 months after the outbreak of Middle East respiratory syndrome in South Korea. BMC Public Health 20: 605. https://doi.org/10.1186/s12889-020-08726-1

Poyiadji, N., Shahin, G., Noujaim, D., Stone, M., Patel, S. \& Griffith, B. (2020). COVID-19-associated acute hemorrhagic necrotizing encephalopathy: Imaging features. Radiology 296: E119-E120. https://doi.org/10.1148/radiol.2020201187

Qi, X., Keith, K.A. \& Huang, J.H. (2020). COVID-19 and stroke: A review. Brain Hemorrhages 2: 76-83. https://doi.org/10.1016/ j.hest.2020.11.001

Radbel, J., Narayanan, N. \& Bhatt, P.J. (2020). Use of tocilizumab for COVID-19-induced cytokine release syndrome: A cautionary case report. Chest 158: e15-e19. https://doi.org/ 10.1016/j.chest.2020.04.024

Ragab, D., Salah Eldin, H., Taeimah, M., Khattab, R. \& Salem, R. (2020). The COVID-19 cytokine storm; what we know so far. Frontiers in Immunology 11: 1446. https://doi.org/ 10.3389/fimmu.2020.01446

Rana, A. \& Musto, A.E. (2018). The role of inflammation in the development of epilepsy. Journal of Neuroinflammation 15: 144. https://doi.org/10.1186/s12974-018-1192-7

Reyes, A., Corrales, N., Gálvez, N.M.S., Bueno, S.M., Kalergis, A.M. \& González, P.A. (2020). Contribution of hypoxia inducible factor-1 during viral infections. Virulence 11: 1482-1500. https://doi.org/10.1080/21505594.2020.1836904

Reynolds, J.L. \& Mahajan, S.D. (2021). SARS-COV2 alters blood brain barrier integrity contributing to neuroinflammation. Journal of Neuroimmune Pharmacology 16: 46. https://doi.org/10.1007/s11481-020-09975-y

Ritchie, A.I. \& Singanayagam, A. (2020). Immunosuppression for hyperinflammation in COVID-19: a double-edged sword? The Lancet 395: 1111. https://doi.org/10.1016/S01406736(20)30691-7

Sarkar, R., Mitra, S., Chandra, P., Saha, P., Banerjee, A., Dutta, S. \& Chawla-Sarkar, M. (2021). Comprehensive analysis of genomic diversity of SARS-CoV-2 in different geographic regions of India: an endeavour to classify Indian SARSCoV-2 strains on the basis of co-existing mutations. Archives of Virology 166: 801-812. https://doi.org/10.1007/ S00705-020-04911-0
Sato, T., Ueha, R., Goto, T., Yamauchi, A., Kondo, K. \& Yamasoba, T. (2021). Expression of ACE2 and TMPRSS2 proteins in the upper and lower aerodigestive tracts of rats: Implications on COVID 19 infections. The Laryngoscope 131: E932-E939. https://doi.org/10.1002/lary.29132

Snyder, D.J. \& Bartoshuk, L.M. (2016). Oral sensory nerve damage: Causes and consequences. Reviews in Endocrine and Metabolic Disorders 17: 149-158. https://doi.org/10.1007/ s11154-016-9377-9

Steinberg, K.P., Hudson, L.D., Goodman, R.B., Lee Hough, C., Lanken, P.N., Hyzy, R., Arbor, A., Taylor Thompson, B. \& Ancukiewicz, M. (2006). Efficacy and safety of corticosteroids for persistent acute respiratory distress syndrome. New England Journal of Medicine 354: 1671-1684. https://doi.org/ 10.1056/NEJMoa051693

Tham, A.C., Thein, T.L., Lee, C.S., Tan, G.S.E., Manauis, C.M., Siow, J.K., Leo, Y.S. \& Lim, M.Y. (2021). Olfactory taste disorder as a presenting symptom of COVID-19: a large single-center Singapore study. European Archives of OtoRhino-Laryngology 278: 1853-1862. https://doi.org/10.1007/ s00405-020-06455-0

Tisoncik, J.R., Korth, M.J., Simmons, C.P., Farrar, J., Martin, T.R. \& Katze, M.G. (2012). Into the Eye of the Cytokine Storm. Microbiology and Molecular Biology Reviews 76: 16-32. https://doi.org/10.1128/mmbr.05015-11

Troyer, E.A., Kohn, J.N. \& Hong, S. (2020). Are we facing a crashing wave of neuropsychiatric sequelae of COVID19? Neuropsychiatric symptoms and potential immunologic mechanisms. Brain, Behavior, and Immunity 87: 34-39. https://doi.org/10.1016/j.bbi.2020.04.027

Umapathi, T., Kor, A.C., Venketasubramanian, N., Lim, C.C.T., Pang, B.C., Yeo, T.T., Lee, C.C., Lim, P.L., Ponnudurai, K., Chuah, K.L. et al. (2004). Large artery ischaemic stroke in severe acute respiratory syndrome (SARS). Journal of Neurology 251: 1227-1231. https://doi.org/10.1007/s00415-004-0519-8

Umapathi, T., Quek, W.M.J., Yen, J.M., Khin, H.S.W., Mah, Y.Y., Chan, C.Y.J., Ling, L.M. \& Yu, W.Y. (2020). Encephalopathy in COVID-19 patients; viral, parainfectious, or both? eNeurologicalSci 21: 100275. https://doi.org/10.1016/ j.ensci.2020.100275

Walls, A.C., Park, Y.J., Tortorici, M.A., Wall, A., McGuire, A.T. \& Veesler, D. (2020). Structure, function, and antigenicity of the SARS-CoV-2 spike glycoprotein. Cell 181: 281-292.e6. https://doi.org/10.1016/j.cell.2020.02.058

Whittaker, A., Anson, M. \& Harky, A. (2020). Neurological manifestations of COVID-19: A systematic review and current update. Acta Neurologica Scandinavica 142: 14-22. https://doi.org/10.1111/ane.13266

World Health Organisation (WHO). (2021). Naming the coronavirus disease (COVID-19) and the virus that causes it. https://www.who.int/emergencies/diseases/novelcoronavirus-2019/technical-guidance/naming-thecoronavirus-disease-(covid-2019)-and-the-virus-thatcauses-it. Accessed 25 February 2021.

Wijeratne, T. \& Crewther, S. (2020). Post-COVID 19 Neurological Syndrome (PCNS); a novel syndrome with challenges for the global neurology community. Journal of the Neurological Sciences 419: 117179. https://doi.org/10.1016/j.jns.2020. 117179

Wijeratne, T. \& Crewther, S. (2021). COVID-19 and long-term neurological problems: Challenges ahead with PostCOVID-19 neurological syndrome. Australian Journal of General Practice 50. https://doi.org/10.31128/ajgp-covid-43 
Wu, C., Chen, X., Cai, Y., Xia, J., Zhou, X., Xu, S., Huang, H., Zhang, L., Zhou, X., Du, C. et al. (2020a). Risk factors associated with acute respiratory distress syndrome and death in patients with Coronavirus Disease 2019 pneumonia in Wuhan, China. JAMA Internal Medicine 180: 934-943. https://doi.org/10.1001/jamainternmed.2020.0994

Wu, Y., Xu, X., Chen, Z., Duan, J., Hashimoto, K., Yang, L., Liu, C. \& Yang, C. (2020b). Nervous system involvement after infection with COVID-19 and other coronaviruses. Brain, Behavior, and Immunity 87: 18-22. https://doi.org/10.1016/ j.bbi.2020.03.031

Xia, H. \& Lazartigues, E. (2010). Angiotensin-converting enzyme 2: Central regulator for cardiovascular function. Current Hypertension Reports 12: 170-175. https://doi.org/10.1007/ s11906-010-0105-7

Xiang, P., Xu, X., Gao, L., Wang, H., Xiong, H. \& Li, R. (2020). First case of 2019 novel coronavirus disease with encephalitis. ChinaXiv 202003 [Preprint].

Xu, X., Han, M., Li, T., Sun, W., Wang, D., Fu, B., Zhou, Y., Zheng, X., Yang, Y., Li, X. et al. (2020). Effective treatment of severe COVID-19 patients with tocilizumab. Proceedings of the National Academy of Sciences of the United States of America 117: 10970-10975. https://doi.org/10.1073/pnas.2005615117

Zegarra-Valdivia, J.A., Chino-Vilca, B.N., Tairo-Cerron, T., Munive, V., Lastarria-Perez, C. \& Ames-Guerrero, R.J. (2020). Neurological components in Coronavirus induced disease: A review of the literature related to SARS, MERS, and COVID-19. Neurology Research International 2020: 6587875. https://doi.org/10.1155/2020/6587875
Zhang, Q.L., Ding, Y.Q, Hou, J.L., He, L., Huang, Z.X., Wang, H.J., Cai, J.J., Zhang, J.H., Zhang, W.L., Geng, J. et al. (2003). Detection of severe acute respiratory syndrome (SARS)associated coronavirus RNA in autopsy tissues with in situ hybridization. Academic Journal of the First Medical College of PLA 23: 1125-1127.

Zhang, R., Wu, Y., Zhao, M., Liu, C., Zhou, L., Shen, S., Liao, S., Yang, K., Li, Q. \& Wan, H. (2009). Role of HIF-1 $\alpha$ in the regulation ACE and ACE2 expression in hypoxic human pulmonary artery smooth muscle cells. American Journal of Physiology - Lung Cellular and Molecular Physiology 297: L631-L640. https://doi.org/10.1152/ajplung.90415.2008

Zhang, S.F., Tuo, J.L., Huang, X.B., Zhu, X., Zhang, D., Zhou, K., Yuan, L., Luo, H.J., Zheng, B.J., Yuen, K.Y. et al. (2018). Epidemiology characteristics of human coronaviruses in patients with respiratory infection symptoms and phylogenetic analysis of HCoV-OC43 during 2010-2015 in Guangzhou. PLoS ONE 13: e0191789. https://doi.org/10.1371/ journal.pone.0191789

Zhao, H., Shen, D., Zhou, H., Liu, J. \& Chen, S. (2020). GuillainBarré syndrome associated with SARS-CoV-2 infection: causality or coincidence? The Lancet Neurology 19: 383384. https://doi.org/10.1016/S1474-4422(20)30109-5 